\title{
O teletrabalho como política pública de inclusão social das pessoas com deficiência no Brasil
}

\author{
Teleworking as a public policy for social inclusion of people with di- \\ sabilities in Brazil
}

\author{
Wellington Rodrigo Lozano da Silva \\ Centro Universitário FIEO - UNIFIEO
}

LEANDRO GILIO

Escola Superior de Agricultura “Luiz de Queiroz”, Universidade de São Paulo (USP)

RESUmo Este estudo tem como objetivo avaliar as possibilidades do teletrabalho, lançando foco sobre a regulamentação legal dessa modalidade de trabalho, em especial no que se refere à nova redação do Artigo $6^{\circ}$. da Consolidação das Leis do Trabalho (CLT) e às inovações trazidas pela reforma trabalhista aprovada em 2017. Também se propõe uma reflexão sobre políticas públicas de emprego no Brasil e de inclusão social, mais especialmente no que tange às possibilidades para pessoas com deficiência ou dificuldades de mobilidade, que poderiam ser beneficiadas com a promoção do teletrabalho. Avalia-se que o teletrabalho pode abrir oportunidades e postos de trabalho para pessoas com deficiência e dificuldades de mobilidade, porém o tema ainda requer maior atenção no que se refere à pesquisa científica e políticas públicas voltadas à temática.

Palavras-chave: Teletrabalho. Políticas públicas. Inclusão social.

\begin{abstract}
The present work portrays the modality of telework as an inevitable consequence to our society in face of the profound changes caused by the technological advances in labor relations which allow the work activities to be done outside the employer's headquarters. It also analyzes the legal regulations of this work modality, especially regarding the new wording of the $6^{\text {th }}$ article in labor laws and the innovations brought up by the labor reform approved in 2017. It is also proposed a reflection on public employment policies in Brazil and on social inclusion, especially regarding the possibilities for people with disabilities or mobility difficulties that could benefit from the promotion of teleworking. It is argued that telework can open opportunities and jobs for people with disabilities and mobility difficulties, but the subject still requires more attention regarding scientific research and public policies on the subject.
\end{abstract}

Keywords: Telework. Public POLICIES. Social inclusion. 


\section{INTRODUÇão}

O acelerado desenvolvimento de tecnologias da informação e comunicação, nas últimas décadas, possibilitou a evolução e o surgimento de novas formas de interação em sociedade, rompendo com barreiras espaço-temporais anteriormente estabelecidas, o que resultou, entre outros efeitos, em um consequente processo de reestruturação das organizações e das relações trabalhistas. Nesse contexto, verifica-se a emergência da modalidade de teletrabalho, em que ocorre a transposição do controle físico do empregador para o meio virtual e a desconcentração do ambiente de trabalho. Segundo Estrada (2017), o teletrabalho é também aquele realizado com ou sem subordinação por meio do uso de antigas e novas formas de telecomunicação em virtude de uma relação de trabalho, permitindo a sua execução a distância, prescindindo da presença física do trabalhador em lugar específico de trabalho.

A opção pelo teletrabalho pode trazer benefícios, como a redução de custos e maiores possibilidades de contratação de mão de obra, por parte dos empregadores; e a minimização de problemas relacionados à mobilidade, por parte das pessoas ocupadas. No Brasil, o teletrabalho é uma realidade crescente. A pesquisa Home Office Brasil, realizada pela Sociedade Brasileira de Teletrabalho e Teleatividades (SOBRAAT) (2016), feita com 325 empresas de diferentes segmentos e portes, de diversas regiões do país, apresentou três movimentos distintos de crescimento da prática do teletrabalho em comparação ao estudo anterior, de 2014: 50\% de aumento no número de empresas que estão implantando a prática, $15 \%$ de aumento no número de empresas que estão estudando a implantação da prática e de $28 \%$ de aumento na formalização da prática. E esse número tende a crescer ainda mais, haja vista o fato de que várias empresas estão adotando essa modalidade, de maneira integral ou parcial.

Porém, tal expediente ainda se configura como desafiador para formuladores de políticas públicas, legisladores e demais operadores do direito, diante da atualidade e das novas complexidades que emergem do crescimento por tal modalidade de relação de trabalho.

Posto isso, inicialmente este estudo realiza uma análise da importância dos dispositivos inseridos na CLT por meio da Lei $12.551 / 2011$, ao alterar o teor do seu artigo $6^{\circ}$., equiparando os efeitos jurídicos da subordinação exercida por meios telemáticos e informatizados àquela exercida por meios pessoais e diretos. Também é abordada a regulamentação do teletrabalho por intermédio da Lei 13.467/2017, mais conhecida como Reforma Trabalhista. Apresenta-se também um breve conceito e o histórico acerca da temática das políticas públicas no Brasil.

Como objetivo, também se avalia a possibilidade de associação do teletrabalho com políticas públicas de inclusão social da pessoa com deficiência. Vale ressaltar que a pessoa com deficiência (PCD), principalmente nas grandes cidades brasileiras, encontra no teletrabalho um agente facilitador da inclusão no mercado de trabalho. Fatores como a dificuldade em chegar ao local de trabalho devido à distância, à precariedade do transporte público $\mathrm{e}$ às barreiras urbanas, levam à certeza de que o trabalho a distância é fundamental. Nesse cenário, o teletrabalho, como política pública de inclusão, pode ser visto como um agente provocador de profundas mudanças no mercado e na sociedade como um todo. 
Neste estudo, adotou-se o método dedutivo, com caráter descritivo e explicativo, amparado em uma pesquisa bibliográfica, por meio da leitura analítica de obras doutrinárias, legislação constitucional e infraconstitucional, jurisprudências acerca do tema, revistas jurídicas, e textos científicos.

\section{TeletrabalHo: CONCEITO, CONTEXTO E REgUlaMentaÇÃo}

O teletrabalho emergiu em meio ao desenvolvimento dos meios de comunicação e dos sistemas de informática que dinamizaram as relações laborais. $\mathrm{O}$ avanço tecnológico, nesse sentido, permitiu o surgimento do teletrabalhador, que passou a realizar suas atividades, seja de forma parcial ou total, em local distinto do estabelecimento do empregador, por intermédio de tecnologias, possibilitando uma melhor eficácia e controle do serviço prestado.

Notadamente, com relação ao conceito de teletrabalho não existe um consenso por parte dos doutrinadores. O conceito mais aceito é o adotado pela Organização Internacional do Trabalho que, segundo Martino, (2001) pode ser definido como:

\footnotetext{
“(...) uma forma de trabalho que é executado em um local distante do escritório central ou instalação de produção, onde o trabalhador não tem nenhum contato pessoal com colegas de trabalho e, também aquela em que é desenvolvido com a ajuda de uma nova tecnologia que possibilita essa separação, promovendo a comunicação" (MARTINO, 2001, p. 3).
}

Ancorado nesse conceito, extrai-se que o teletrabalho é aquele realizado em local diverso do espaço físico da empresa, mediante o uso de tecnologias da informação que interligam o teletrabalhador por meio do computador ou outro equipamento de comunicação ao sistema central da empresa. Já os meios telemáticos podem ser definidos como um conjunto de tecnologias da comunicação e da informação que transmitem dados que possibilitam o acesso ao teletrabalhador em qualquer lugar que ele estiver laborando.

Existem diversas terminologias que são utilizadas para descrever o trabalho distância, como e-workplace, home-based telework, new technology homework e trabalho compartilhado (COSTA, 2003, p. 123). No Brasil, as expressões comumente utilizadas na literatura científica sobre o tema são Teletrabalho e Trabalho Remoto.

Importante ressaltar que existe uma diferença fundamental entre o teletrabalho e o trabalho em domicílio. Ainda que ambos sejam tipos de trabalho a distância, o trabalho em domicílio é essencialmente caracterizado pelo local em que é prestado, ou seja, a residência do trabalhador, fato que não é característica intrínseca ao teletrabalho, que pode ser exercido em qualquer ambiente com a utilização dos meios que permitam o acesso à empresa empregadora. Conforme Rosenfield (2005), o avanço de tecnologias de comunicação como fax, celular, laptop e internet tornaram possível trabalhar de quase qualquer lugar, o que ampliou as possibilidades da relação empregador e empregado.

Analisando seus aspectos históricos, o teletrabalho teve seu marco de conceitualização na década de 1950, quando Norbert Winner mencionou em seus trabalhos pela primeira vez o conceito de trabalho a distância. No livro The Human Use of Human Being - Cybernetics and Society (WINNER, 1954) há uma citação sobre um arquiteto europeu que, por 
intermédio de meios de comunicação, fazia a distância toda supervisão de um imóvel que estava sendo construído nos Estados Unidos.

Em meados da década de 1970, o mundo passava pela crise do petróleo e o preço dos combustíveis passaram a sofrer oscilações significativas. Em razão disso, o deslocamento dos trabalhadores de suas residências para a empresa tornou-se mais oneroso, o que culminou no incentivo a alternativas por parte das organizações.

No ano de 1973, Jack M. Nilles, físico e então funcionário da National Aeronautics and Space Administration (NASA), lançou a ideia de modificar a clássica relação entre o local de trabalho e o trabalhador, sob o argumento de que os trabalhadores poderiam exercer suas atividades a partir de suas residências, com a utilização de ferramentas e recursos da computação e das telecomunicações. Nilles, por esse pioneirismo, é considerado precursor do teletrabalho e autor de várias obras sobre o tema. ${ }^{1}$

A partir desse entendimento, o conceito de teletrabalho evoluiu e, por conseguinte, ganhou maior espaço para essa nova relação de trabalho a distância. Ainda na década de 70, uma empresa de seguros de Los Angeles ${ }^{2}$ foi a primeira a implantar o projeto piloto de teletrabalho objetivando evitar os deslocamentos dos trabalhadores até a sede do empregador para reduzir os congestionamentos. O resultado desse projeto foi positivo e resultou no livro The Telecommunications transportation trade off-options for tomorrow (NILLES, 1974) no qual foram inicialmente conceituados teleworking e telecommuting. ${ }^{3}$

Nos anos seguintes, houve um grande impulso para o teletrabalho, principalmente com o desenvolvimento nos setores de informática e de telecomunicações. No contexto brasileiro, tem-se como marco a criação da Sociedade Brasileira de Teletrabalho e Teleatividades (SOBRATT), sociedade civil, sem fins lucrativos, que desde então se tornou referência relevante sobre os temas do teletrabalho e diversas formas flexíveis de realização do trabalho no Brasil. ${ }^{4}$

De acordo com Abrantes (2019), a estimativa é de que atualmente cerca de 10 milhões de pessoas já exerçam suas profissões sob a modalidade de teletrabalho no Brasil, algumas apenas de forma virtual e outras mantêm parte dos funcionários nesse segmento, em instituições privadas e públicas.

Nesse contexto, o teletrabalho é regulamentado em vários países do mundo. Na América do Sul, Chile, Colômbia e Peru o teletrabalho encontra-se legalmente amparado pelas Leis $n^{\circ} .19 .759 / 2002 ;^{5} 1.221 / 2008$ e Lei $n^{\circ} .30 .036 / 2013$, respectivamente.

1 Entre as obras de Jack Nilles podemos destacar: Making the Telecommuting Happen. A guide for telemanagers and telecommuters, New York: International Thomson Publ./ van Nostrand Reinhold, 1994; Fazendo do Teletrabalho uma realidade. Trad. Eduardo Pereira Ferreira, São Paulo: Futura, 1997; Managing Telework. Strategies for managing the virtual workforce, New York: Wiley, 1998.

2 Por razões relacionadas ao congestionamento de tráfego e poluição atmosférica, Los Angeles implantou um plano que criou 40 mil teletrabalhadores. Com essa ação, a cidade teve um ganho de 180 milhões de dólares devido à diminuição dos custos gerais e do aumento da produtividade (TROPE, 1999, p. 19).

3 O termo telecommuting deriva da palavra inglesa commuting, que quer dizer ida e volta de casa ao trabalho e foi utilizado por Nilles em sua obra The Telecommunications transportation tradeoff-options for tomorrow.

4 SOCIEDADE BRASILEIRA DE TELETRABALHO E TELEATIVIDADES (SOBRATT). Quem Somos. São Paulo, 2015. Disponível em: http://www.sobratt.org.br/index.php/quem-somos/historia/. Acesso em: 21 jan. 2019.

5 A lei chilena $\mathrm{n}^{\circ}$. 19.759/2002 modificou os artigos $8^{\circ}$. e 22 existentes no Código de Trabalho. 
Em determinados países em via de regulamentação mencionam-se o Uruguai (Projeto de Lei $n^{\circ}$. 16/2010) e Argentina (Projeto de Lei no. 2.337/2007 e 3.498/2010).

Em países europeus, como Portugal, encontra-se elencado nos artigos 233 até 248 do Código de Trabalho Português de 01/12/2003 e, na Itália, permite-se o teletrabalho na administração pública com alicerce na Lei no ${ }^{\circ} 191$ de 16/06/1998. ${ }^{6}$

Importante destacar que o Acordo Marco Europeu de Teletrabalho ${ }^{7}$ assinado em 16/07/2002 na cidade de Bruxelas estabeleceu um marco geral do teletrabalho na União Europeia. Em que pese a não obrigatoriedade dos Estados-Membros na adoção desse acordo, diversos países o utilizam como referência para o estabelecimento de regras locais para trabalho a distância.

No Brasil, o Teletrabalho foi citado na Lei $\mathrm{n}^{\mathrm{o}}$. $12.551 / 2011$, que alterou o artigo $6^{\circ}$. da CLT, acrescentando o parágrafo único apenas com o fito de equiparar o trabalho feito no estabelecimento do empregador ao realizado à distância. Para uma regulamentação mais abrangente da matéria foi aprovada a Lei n. 13.467, de 13 de julho de 2017, que trouxe, ao concretizar a reforma trabalhista, alterações na CLT, com a inserção dos Artigos 75-A a 75-E que tratam do teletrabalho e seus desdobramentos. Um maior detalhamento da legislação brasileira relacionada ao tema é descrito na seção seguinte.

\section{A nova redação do Artigo $6^{\circ}$. da CLT e a reforma trabalhista}

Anteriormente à publicação da Lei $\mathrm{n}^{\mathrm{o}}$. $12.551 / 2011,{ }^{8}$ o teletrabalho no direito brasileiro era conduzido, por analogia, pelo caput do artigo $6^{\circ}$. da Consolidação das Leis do Trabalho, no qual não havia distinção entre o trabalho realizado no estabelecimento do empregador e o trabalho feito no domicílio, desde que a relação de emprego estivesse caracterizada. O mesmo dispositivo legal antevia no Artigo 83 que o empregador deveria pagar salário mínimo ao trabalhador em domicílio.

Como se pode averiguar, o trabalho a distância não era mencionado na CLT, tendo em vista que apenas se fazia alusão ao trabalho executado no domicílio do empregado. Essa omissão era palco de algumas discussões no tocante às diferenciações existentes entre ambos, pois o trabalho realizado no domicílio do empregado tinha como característica a execução de trabalhos manuais e no teletrabalho a execução de tarefas complexas e com o uso dos meios telemáticos.

Com o advento da Lei $\mathrm{n}^{\circ}$. 12.551/2011 (publicada em 15 de dezembro de 2011), a redação do artigo $6^{\circ}$. da CLT foi alterada, inclusive com a inserção do parágrafo único que passou a prognosticar essa modalidade de trabalho.

\footnotetext{
6 A lei italiana 191/1998 define como trabalho a distância todo o trabalho realizado pelo trabalhador da administração pública exercido em local fora da empresa dotado de idoneidade e com o suporte de TICs que permitam a conectividade com a administração.

7 Acuerdo Marco Europeo sobre Teletrabajo. Disponível em: <http://www. creex.es/www.creex.es/prc/TELETRABAJO.pdf.> Acesso em: 6 nov. 2018.

8 Lei $n^{\circ}$. 12.551/2011 foi sancionada pela presidente Dilma Rousseff e alterou o artigo $6^{\circ}$. da CLT com a finalidade de equiparar os efeitos jurídicos da subordinação exercida por meios telemáticos e informatizados àquela exercida pelos meios diretos e pessoais.
} 
Artigo 6o. Não se distingue entre o trabalho realizado no estabelecimento do empregador, o executado no domicílio do empregado e o realizado a distância, desde que estejam caracterizados os pressupostos da relação de emprego (BRASIL, 1943).

Parágrafo único. Os meios telemáticos e informatizados de comando, controle e supervisão se equiparam, para fins de subordinação jurídica, aos meios pessoais e diretos de comando, controle e supervisão do trabalho alheio (Alterações trazidas pela Lei $\mathrm{n}^{\circ}$. 12.551/2011).

Com a inclusão desse parágrafo, foram igualados os efeitos jurídicos da dependência pelos meios telemáticos e informatizados com aqueles executados no domicílio do empregado ou realizados na modalidade tradicional por meios subjetivos e diretos no estabelecimento do empregador.

Adverte-se que a Lei $\mathrm{n}^{\mathrm{o}}$. 12.551/2011 somente reconheceu a modalidade de teletrabalho e o uso dos meios informatizados na relação de trabalho. Frise-se que em nenhum momento regulamentou o teletrabalho ou retratou outras questões como a jornada de trabalho e horas extras.

Uma regulamentação mais abrangente foi elaborada apenas em 2017, com a reforma trabalhista. O texto reformador, que insere o Capítulo II-A na Consolidação das Leis do Trabalho, regula o teletrabalho por meio das disposições contidas no Artigo 75-A e seguintes.

No conceito legal ali fixado, considera-se teletrabalho a prestação de serviços preponderantemente fora das dependências do empregador, com a utilização de tecnologias de informação e de comunicação que, por sua natureza, não se constituam como trabalho externo. O parágrafo único do Artigo 75-B ainda aduz que o comparecimento às dependências do empregador para a realização de atividades específicas que exijam a presença do empregado no estabelecimento não descaracteriza o regime de teletrabalho.

No que se refere às formalidades contratuais, a prestação de serviços na modalidade de teletrabalho deverá constar expressamente do contrato individual de trabalho, que especificará as atividades que serão realizadas pelo empregado. Já no que se refere às alterações contratuais, especificam-se nos parágrafos $1^{\circ}$. e $2^{\circ}$. do Artigo $75-\mathrm{C}$ que:

$\S 1$ 1o Poderá ser realizada a alteração entre regime presencial e de teletrabalho, desde que haja mútuo acordo entre as partes, registrado em aditivo contratual. $\S 2$ o Poderá ser realizada a alteração do regime de teletrabalho para o presencial por determinação do empregador, garantido prazo de transição mínimo de quinze dias, com correspondente registro em aditivo contratual.

Do mesmo modo, segue o texto legal determinando que as disposições relativas à responsabilidade pela aquisição, manutenção ou fornecimento dos equipamentos tecnológicos e da infraestrutura necessária e adequada à prestação do trabalho remoto, bem como, ao reembolso de despesas arcadas pelo empregado serão previstas em contrato escrito.

No que se refere aos demais temas correlatos a essa modalidade contratual, o legislador cuidou de estabelecer que as utilidades (equipamentos tecnológicos) fornecidas para a realização do teletrabalho não integram a remuneração do empregado, assim como caberá ao empregador a instrução dos empregados quanto às precauções a tomar a fim de evitar 
doenças e acidentes de trabalho. Do mesmo modo, o empregado deverá assinar termo de responsabilidade comprometendo-se a seguir as instruções fornecidas pelo empregador.

\section{EVoluÇÃo do TEMA "POLÍTICAS PÚBLICAS" NO BRASIL E O TELETRABALHO COMO POLÍTICA SOCIAL}

Considerada uma área do conhecimento contida na Ciência Política, as políticas públicas foram adquirindo autonomia e status científico a partir de meados do século XX, na Europa e nos Estados Unidos (DIAS; MATOS 2017).

Inicialmente, a sociedade civil era excluída do processo de sua formulação, de implementação de programas e do controle da ação governamental. A implementação de programas e a alocação de recursos eram influenciadas ora pela relação entre políticos e sua clientela, na base de troca de favores, ora pela lógica corporativa típica da cidadania regulada (LAMB; KAUER, 2014).

Ademais, o modelo de provisão estatal, hegemônico nos países capitalistas ocidentais pós-guerra, teria sido responsável, inclusive, pelo refluxo de iniciativas da sociedade civil e do mercado, sendo vista a proteção social, no limite, como responsabilidade exclusiva do Estado (LAMB; KAUER, 2014).

O contexto histórico de políticas públicas no Brasil é recente, começando nos anos 1930, quando o Brasil passa por uma transformação muito grande, pois na década anterior era um país rural e agrícola. O censo de 1920 revelava que 30\% da população brasileira vivia nas cidades e 70\%, no campo. Cinquenta anos depois, ocorria o inverso $-70 \%$ nas cidades e $30 \%$ no campo. Até 1930 , a economia do Brasil era uma economia agrícola:

\footnotetext{
Em 1980, o Brasil era o oitavo PIB industrial do mundo. (...). Isto nos dá uma ideia da mudança de perfil na sociedade e na economia em meio século. O que alguns países levaram séculos para fazer, o Brasil fez em cinquenta, sessenta anos. Transformou-se numa potência industrial média, com a maior parcela da sua gente morando nas cidades. Este é o perfil atual do Brasil. Para entender os dias de hoje, é necessário saber que Estado tínhamos anteriormente e que heranças e traços foram se fixando nesse percurso (BACELAR, 2003, p. 1).
}

Essencialmente, o que caracterizava o Estado brasileiro nesse período (1920-1980) era seu caráter desenvolvimentista, conservador, centralizador e autoritário, sem preocupação com o bem-estar social (BACELAR, 2003). Além disso, era o promotor do desenvolvimento e não o transformador das relações da sociedade.

Até o início dos anos 1980, as políticas públicas se caracterizavam, em primeiro lugar, pela centralização decisória e financeira na esfera federal, cabendo aos Estados e municípios, quando estes eram envolvidos em uma política específica, compreende-se que tais políticas eram forma de poder oriundo do Estado (LAMB; KAUER, 2014, p. 7).

Já as últimas décadas registraram o ressurgimento da importância do campo de conhecimento denominado políticas públicas, assim como das instituições, regras e modelos que regem sua decisão, elaboração, implementação e avaliação (SOUZA, 2006, p. 20). 
Ademais, a discussão política hoje, qualquer que seja, deve passar necessariamente pela consideração do fenômeno da globalização, pois constitui um processo que envolve toda a humanidade (DIAS; MATOS, 2017, p. 32).

Outro ponto importante é que o Estado não pode ser reduzido à burocracia, aos organismos estatais que conceberiam e implementariam as políticas públicas (HOFLING, 2001, p. 32). Portanto, estas são aqui compreendidas como as de responsabilidade do Estado, quanto à implementação e manutenção a partir de um processo de tomada de decisões que envolvem órgãos públicos e diferentes organismos e agentes da sociedade relacionados à política implementada. Nesse sentido, políticas públicas não podem ser reduzidas a políticas estatais.

Hodiernamente os indivíduos participam do ciclo das políticas públicas - definição da agenda, elaboração, implementação e avaliação. Sendo assim, escolhem entre diversas alternativas quais serão as políticas e as ações a serem praticadas pelo governo para o alcance de objetivos preestabelecidos. Tratando-se de um governo democrático, as preferências e interesses passam a ser constantemente negociadas, e envolvem os interesses de diversos atores que compõem o aparato estatal.

Quando os olhares são voltados para a inclusão social por meio de políticas públicas, no Brasil, sob a vigência da Constituição da República de 1934 - influenciada pela Constituição de Weimar, tem-se as primeiras referências aos direitos sociais, onde reiterando o princípio da igualdade, dedicou um título para a ordem econômica e social, estabelecida de modo que possibilitasse, a todos, uma existência digna (PORTO; DIEHL; 2016, p. 13). Essa estrutura, onde os direitos sociais estavam dispostos dentro do título da ordem econômica e social perdurou nas constituições posteriores, entretanto, com a promulgação da Constituição da República de 1988, os direitos sociais foram erigidos para a categoria de direitos fundamentais com expressa previsão no segundo capítulo - Dos Direitos Sociais (PORTO; DIEHL, 2016, p. 13).

Portanto, ao classificar os direitos sociais como direitos fundamentais, compreende-se que são situações jurídicas sem as quais as pessoas não se realizam, não convivem e, às vezes, nem mesmo sobrevivem e, nesse sentido, todos os homens devem ser tratados de forma igualitária não apenas formalmente, mas concretamente efetivados (PORTO; DIEHL, 2016, p. 14).

Diante disso, podemos dizer que o início da reforma estatal se deu por meio da Constituição da República de 1988, ao colocar em prática a democratização do acesso a serviços e à participação cidadã. Assim, ocorreu, nesse período, um deslocamento para o foco das políticas públicas no Brasil, partindo-se para a produção de ferramentas que se destinassem a examinar as verdadeiras necessidades sociais (PORTO; DIEHL, 2016, p. 14).

Sob a égide do vigente texto constitucional, a temática da assistência social e das medidas inclusivas são tratadas no Título VIII - Da Ordem Social, mais especificamente dentro da Seção IV do Capítulo II.

Conforme previsão contida no Artigo 203, a assistência social será prestada a quem dela necessitar, independentemente de contribuição à seguridade social, e tem, entre outros objetivos: III - a promoção da integração ao mercado de trabalho; e IV - a habilitação e reabilitação das pessoas portadoras de deficiência e a promoção de sua integração à vida comunitária. 
Além disso, o Artigo 204 determina que as ações governamentais na área da assistência social serão realizadas com recursos do orçamento da seguridade social, além de outras fontes, e organizadas com base, entre outras, nas diretrizes de participação da população, por meio de organizações representativas, na formulação das políticas e no controle das ações em todos os níveis.

Ademais, no que se refere às políticas públicas voltadas às pessoas com deficiência, não se pode deixar de mencionar a promulgação da Lei 12.711, de 29 de agosto de 2012, que dispõe sobre o ingresso nas universidades federais e nas instituições federais de ensino técnico de nível médio, mais conhecida como lei de cotas e o mais recente Estatuto da Pessoa com Deficiência (Lei 13.146, de 6 de julho de 2015).

Em razão dessa nova conjuntura, a compreensão de alguns conceitos que perfazem o universo das políticas públicas revela-se a chave-mestra para a promoção e efetivação de direitos e garantias sociais, especialmente no que se refere à efetivação da cidadania na era da globalização.

Ademais, o estudo sobre as políticas públicas deve ser feito de forma integrada com a compreensão do papel do Estado e da própria sociedade dos dias atuais. No cenário moderno, as políticas públicas são o resultado da própria política, e devem ser compreendidas "à luz das instituições e dos processos políticos, os quais estão intimamente ligados às questões mais gerais da sociedade" (PORTO; DIEHL, 2016, p. 14).

Por fim, as questões sociais demandam uma profunda reflexão e ação frente as suas diferentes necessidades e evitar o acirramento delas é tarefa e desafio de todos os setores da sociedade envolvidos na construção da democracia como um valor humano de garantia universal de direitos sociais, políticos e jurídicos. Assim, ao discutirmos sobre o Teletrabalho e sua importância como política pública de inclusão social, temos que a mudança legislativa realizada na CLT, ao regulamentar o tema, possibilitará uma maior inclusão no mercado de trabalho do cidadão, que muitas vezes acaba marginalizado em razão de suas limitações, conforme se analisará ne sequência deste trabalho.

\section{O TELETRABALHO COMO FATOR DE INCLUSÃo DE PESSOAS COM DEFICIÊNCIA NO MERCADO DE TRABALHO}

Na realidade atual do mercado de trabalho, a deficiência afeta igualmente os dois polos da relação empregatícia: tanto o lado da oferta (trabalhador) quanto da demanda (necessidade de mão de obra). Pelo lado do trabalhador, um exemplo disso seria a dificuldade de locomoção, que eleva os custos de transporte e reduz o incentivo ao trabalho. Pela ótica do empresário, os empregadores podem hesitar em contratar deficientes ou pagá-los de modo igualitário aos demais, dada a possibilidade de percepção de que a deficiência reduz a produtividade, aumenta os custos de adaptação do ambiente de trabalho ou, simplesmente, por existir a discriminação para com esses indivíduos (CASTRO et al., 2017).

Diante das características intrínsecas ao teletrabalho e da base jurídico-institucional avaliada, onde o teletrabalhador está em condições de igualdade de direitos e obrigações em relação àquele que labora nas dependências do empregador, tem-se que essa modalidade de prestação de serviços pode acarretar uma maior inserção no mercado de trabalho de pessoas 
com deficiência, principalmente no que se refere à mobilidade, propiciando a concorrência em maior grau de igualdade com os demais trabalhadores no universo corporativo.

A reserva de postos de trabalho para deficientes é uma preocupação mundial, tanto que nosso país ratificou a Convenção $159,{ }^{9}$ comprometendo-se com a OIT na adoção de medidas positivas visando à superação das dificuldades dos deficientes. Com intuito de proporcionar condições e facilitar o acesso às vagas para pessoas com deficiência, o artigo 93 da Lei $n^{\circ}$. 8.213/1991 ${ }^{10}$ estabeleceu uma política de cotas obrigando as empresas privadas a reservarem vagas para deficientes.

Após oito anos, o Decreto $n^{\circ}$. 3.298/1999 ${ }^{11}$ instituiu a Política Nacional para a integração da pessoa portadora de deficiência, assegurando o pleno exercício dos direitos individuais e sociais dos deficientes. O órgão responsável por fiscalizar o cumprimento das medidas é o Ministério Público do Trabalho, que criou uma Comissão Nacional para estudar assuntos relacionados à inserção dos deficientes no mercado de trabalho.

Além do princípio da igualdade insculpido no caput do artigo $5^{\circ}$. da Constituição Federal, o artigo $7^{\circ}$., XXXI ${ }^{12}$ do mesmo dispositivo legal preocupou-se em proteger o trabalhador deficiente de qualquer tipo de discriminação. Como se pode verificar, a legislação brasileira protege aqueles que possuem algum tipo de deficiência, seja ela física ou mental e buscam a inserção no mercado de trabalho. A mais recente providência legislativa para a inclusão das pessoas com deficiência no mercado de trabalho e na sociedade como um todo é a já citada Lei 13.146 de 6 de julho de 2015 - Estatuto da Pessoa com Deficiência.

A citada lei que estabeleceu cotas e os demais textos normativos colaboraram muito com a inclusão da pessoa com deficiência. Entretanto, ainda existe um longo caminho para que seja alcançado um nível de inclusão relevante, vencendo o preconceito quanto à diversidade.

Vislumbra-se que nas relações tradicionais de trabalho é grande a discriminação com os deficientes, pois muitas vezes o ambiente de trabalho não possui acessibilidade, os equipamentos não são adequados e o deslocamento até o local de trabalho não é adaptado.

$\mathrm{Na}$ modalidade de teletrabalho, um novo mundo de oportunidades se abre para os deficientes que estão impedidos de se deslocarem ou que encontram alguma barreira arquitetônica dificultando o acesso aos lugares ou de se locomoverem com o uso dos meios de transportes.

Sob esse ponto de vista, a modalidade de teletrabalho opera como um instrumento

9 Disponível em: http://www.planalto.gov.br/ccivil_03/decreto/1990-1994/D0129.htm. Acesso em: 4 nov. 2018.

10 Artigo 93. A empresa com 100 (cem) ou mais empregados está obrigada a preencher de $2 \%$ (dois por cento) a 5\% (cinco por cento) dos seus cargos com beneficiários reabilitados ou pessoas portadoras de deficiência, habilitadas, na seguinte proporção:

I - até 200 empregados...........................................................................................

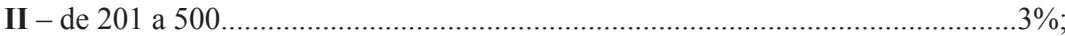

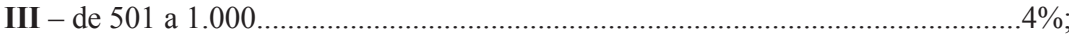

IV - de 1.001 em diante......................................................................................

Disponível em: < http://www.planalto.gov.br/ccivil 03/leis/L8213cons.htm>. Acesso em: 4 nov. 2018.

11 Disponível em: <http://www.planalto.gov.br/ccivil 03/decreto/d3298.htm>. Acesso em: 4 nov. 2018.

12 XXXI - proibição de qualquer discriminação no tocante a salário e critérios de admissão do trabalhador portador de deficiência (BRASIL, 1988). 
que contribui para a diminuição da desigualdade, oportunizando criação de empregos para aqueles que se sentem marginalizados ou desfavorecidos.

O teletrabalho rompe as barreiras geográficas inserindo o trabalhador com deficiência no mercado de trabalho, acabando com os problemas relacionados à locomoção e adaptação do ambiente de trabalho. Quando o trabalhador deficiente estiver executando seus afazeres, desconhecendo a limitação de espaço e locomoção, sua deficiência não será mais encarada como um obstáculo a ser vencido.

Além disso, as empresas cumprem a sua responsabilidade social ao facilitar a empregabilidade da pessoa com deficiência, principalmente dos cadeirantes, por meio do teletrabalho, pois nessa modalidade permite-se a execução de tarefas de maneira produtiva no ambiente residencial adaptado às suas necessidades.

Ademais, o teletrabalho não é exclusividade das organizações privadas e já faz parte da realidade de diversos órgãos públicos, a exemplo do que ocorre no Tribunal Regional do Trabalho da $2^{\text {a }}$ Região, com sede em São Paulo (SP). Naquela instituição, o teletrabalho dos servidores já se encontra regulamentado e também se constitui numa importante ferramenta de inclusão, pois, verificada a adequação de perfil, terão prioridade ao regime de teletrabalho, os servidores com deficiência que lá trabalham.

Ante o apresentado, o ciberespaço não cria óbice para o deficiente, permitindo que ele perceba que não está limitado à deficiência além de ser um aliado garantindo a inserção ou manutenção do trabalhador deficiente no mercado de trabalho, incluindo-o socialmente passando a ser visto como útil para a sociedade e não como mero assistencialismo.

Com a recente regulamentação legislativa do teletrabalho, crescem as possibilidades de uma maior inserção das pessoas com deficiência no mercado, uma vez que o texto legal confere segurança jurídica às partes envolvidas e esclarece pontos que eram controvertidos, viabilizando assim mais contratações e a concretização das políticas públicas que visam à inclusão das pessoas com deficiência.

\section{CONSIDERAÇões FINAIS}

O teletrabalho no Brasil e no mundo, seus aspectos históricos e legislativos, os atores envolvidos e os seus desafios evidenciam que essa modalidade de labor é um componente importante em meio às mudanças na sociedade, proporcionadas pelos avanços tecnológicos. A modalidade do teletrabalho resultou de transformações que revolucionaram o mercado de trabalho por possibilitar ao teletrabalhador prestar suas atividades em lugar diverso da sede do empregador dispondo, para tanto, de meios telemáticos que fazem uma conexão entre os sujeitos da relação empregatícia.

Este presente estudo ressalta que o fenômeno do teletrabalho está sendo cada vez mais explorado pelas empresas, que enxergam nele uma alternativa para a prestação dos serviços em qualquer lugar do mundo, beneficiando não somente os teletrabalhadores e os empregadores, mas toda a sociedade. Também foram avaliados os impactos que os avanços tecnológicos causam nas relações trabalhistas, pois cada vez mais se fazem presentes na vida e na rotina do trabalhador. 
Verifica-se que o teletrabalho pode ser visto como oportunidades de emprego, inclusive para as pessoas com deficiência e dificuldades de mobilidade, dado que permite a adaptação do domicílio do empregado para atender à demanda da empresa, evitando assim seu deslocamento até a sede do empregador.

Diversas são as perspectivas no tocante ao futuro do teletrabalho quando analisadas sob a ótica da flexibilização dos direitos voltados às novas tecnologias. Por abranger uma natureza flexível, o teletrabalho possui um alcance extraterritorial que conecta o teletrabalhador à sede do empregador e, com isso, atendendo às necessidades de um mercado de trabalho cada vez mais globalizado.

Com relação à Lei $n^{\circ}$. 12.551/2011, verificou-se que a mesma não trouxe muitas mudanças, haja vista que referida lei apenas reconheceu o teletrabalho pautando-se nos mesmos direitos trabalhistas que regem o trabalho tradicional. Examinou-se também o teletrabalho regulamentado pela recente Reforma Trabalhista de 2017.

Diante do exposto, observou-se que o tema ainda requer maior atenção por parte da literatura científica, endo em vista a complexidade da temática, com o fim de se buscar uma melhor compreensão de pontos controversos atinentes ao teletrabalho como mecanismo de inserção social do deficiente, sob o enfoque das políticas públicas voltadas a esse fim.

\section{REFERÊNCIAS}

ABRANTES, T. Mais de 26 milhões de americanos já aderiram ao teletrabalho. Revista Exame, São Paulo, 2011. Disponível em: https:/exame.abril.com.br/carreira/mais-de-26-milhoes-de-americanos-ja-aderiram-ao-teletrabalho/. Acesso em: 21 jan. 2019.

BACELAR T. As Políticas Públicas no Brasil: heranças, tendências e desafios. Texto retirado de: Santos Junior, Orlando Alves dos. [et al.] (orgs.). Políticas Públicas e Gestão Local: programa interdisciplinar de capacitação de conselheiros municipais. Rio de Janeiro: FASE, 2003. Disponível em: http://franciscoqueiroz.com.br/portal/phocadownload/gestao/ taniabacelar.pdf. Acesso em: 8 nov. 2018.

BRASIL. Constituição da República Federativa do Brasil. São Paulo: Revista dos Tribunais, 2018.

CASTRO, N. R.; MOREIRA, G. C.; SILVA, R. P. Wage differential and disability in Brazil: a productive or discriminatory effect? ANPEC 2017. Disponível em: $<$ https://www. anpec.org.br/encontro/2017/submissao/files_I/i13-d62e01957a09d5941d800be6f8a5acd5. pdf $>$. Acesso em: 23 jan. 2019.

Consolidação das Leis do Trabalho. Decreto-lei $n^{\circ}$. 5.452, de $1^{\circ}$. de maio de 1943 . Disponível em: http://www.planalto.gov.br/ccivil_03/decretolei/del5452.htm. Acesso em: 10 de nov. 2018. 
COSTA, I. de S.A. da. Poder/saber e subjetividade na construção do sentido do teletrabalho. Tese de Doutorado em Administração. Rio de Janeiro: Fundação Getúlio Vargas, 2003, p. 123.

DIAS R.; MATOS F. Políticas Públicas: Princípios, propósitos e processos. São Paulo: ATLAS, 2017, p. 10 e 11.

ESTRADA, M. M. P. Teletrabalho: Conceitos e a Sua Classificação em Face aos Avanços Tecnológicos. In: STOLZ, Sheila; MARQUES, Carlos Alexandre Michaello (Org.). Teletrabalho, 1. ed. São Paulo, SP: LTr, 2017, p. 12.

HÖFLING E. M. Estado e Políticas (Públicas) Sociais. Cadernos Cedes, n. 55, 2001. Disponível em: http://www.scielo.br/pdf/ccedes/v21n55/5539. acesso em: $1^{\text {o }}$. nov. 2018.

JARDIM, C. C. S. O teletrabalho e suas atuais modalidades. São Paulo: LTr, 2003, p. 37.

LAMB Nairo V. Wester\&KAUER V. Catellan: A Regulamentação do Teletrabalho Como Forma de Promover a Inclusão Social de Pessoas Portadoras de Necessidades Especiais No Mercado De Trabalho. Escola de Administração da UFRGS, 2014, v. 2, n. 18, p. 1-36. Acessado em: 28/10/2018, disponível em: file://C:/Users/Max/Downloads/ Artigo\%20Pesquisado\%20(1).pdf. Acesso em: 14 nov. 2018.

Lei 12.551, de 15 de dezembro de 2011. Altera o artigo $6^{\circ}$. da Consolidação das Leis do Trabalho (CLT), aprovada pelo Decreto-Lei $\mathrm{n}^{\circ} .5 .452$, de $1^{\circ}$. de maio de 1943 , para equiparar os efeitos jurídicos da subordinação exercida por meios telemáticos e informatizados à exercida por meios pessoais e diretos. Disponível em: http://www.planalto.gov.br/ccivil_03/_ato2011-2014/2011/lei/112551.htm. Acesso em: 10 de nov. 2018.

Lei n⿳. 13.467, de 13 de julho de 2017. Altera a Consolidação das Leis do Trabalho (CLT), aprovada pelo Decreto-Lei $n^{\circ} .5 .452$, de $1^{\circ}$. de maio de 1943 , e as Leis $n^{\circ s}$. 6.019, de 3 de janeiro de 1974, 8.036, de 11 de maio de 1990, e 8.212, de 24 de julho de 1991, a fim de adequar a legislação às novas relações de trabalho. Disponível em: http://www.planalto. gov.br/ccivil_03/_Ato2015-2018/2017/Lei/L13467.htm.

MARTINO, V.Di. High road to teleworking, in the to teleworking. OIT, 2001, p. 3.

NILLES, J. M. Managing telework: strategies for managing he virtual workforce. New York: John Wiley \& Sons, 1998.

ROSENFIELD, C. L. Autonomia e trabalho informacional: o teletrabalho. Artigo apresentado no XXIX Encontro Anual da ANPOCS, Caxambu, 2005, p. 11.

SILVA F. G. Allan; MOTA A. Melo, et al. A relação entre Estado e políticas públicas: 
uma análise teórica sobre o caso brasileiro. REVISTA DEBATES, Porto Alegre, v. 11, n. 1, p. 25-42, jan./abr. 2017. Disponível em: http://www.seer.ufrgs.br/debates/article/ view/72132. Acesso em: 12 nov. 2018.

SOCIEDADE BRASILEIRA DE TELETRABALHO E TELEATIVIDADES (SOBRATT). Pesquisa Home Office Brasil 2016 - Teletrabalho e Home Office, uma tendência nas empresas brasileiras. São Paulo, SP, 2016. Disponível em: http:/www.sobratt.org.br/index. php/11-e-12052016-estudo-home-office-brasil-apresenta-o-cenario-atual-da-pratica-no-pais-sap-consultoria/. Acesso em: 7 jan. 2018.

SOUZA Celina. Políticas Públicas: Uma revisão da Literatura. Pesquisadora do Centro de Recursos Humanos (CRH) da Universidade Federal da Bahia. Brasil, 2006. Este artigo é uma versão revista e ampliada de texto publicado anteriormente. Ver Souza (2003). Acesso em: 16 nov. 2018. Disponível em: http://www.scielo.br/pdf/soc/n16/a03n16

TEIXEIRA E. Celso: O Papel das Políticas Públicas no Desenvolvimento Local e na Transformação da Realidade, 2002, v. 8, n. 4, p. 3-28. AATR-BA. Disponível em: http:// www.escoladebicicleta.com.br/politicaspublicas.pdf

TROPE, A. Organização virtual: impactos de teletrabalho nas organizações. Rio de Janeiro: Qualitymark, 1999, p. 19.

Wellington Rodrigo Lozano da Silva

Graduado em Direito pela Universidade Estadual de Maringá (2007). Especialização em Direito do Trabalho e Processo do Trabalho pela Faculdade Damásio (2016). Especialização em Docência do Ensino Superior e Antropologia pela Universidade Cândido Mendes (2018). Mestrando em Direito na área de Positivação e Concretização Jurídica dos Direitos Humanos no Centro Universitário FIEO - UNIFIEO (2018/2019). lozanowell@gmail.com

\section{DAdos do AUTOR}

\section{LEANDRO GILIO}

Doutor e Mestre em Ciências (Economia Aplicada) pela Escola Superior de Agricultura Luiz de Queiroz da Universidade de São Paulo (ESALQ-USP). Especialista em Agroenergia pela Escola Superior de Agricultura Luiz de Queiroz da Universidade de São Paulo (PECEGE/ ESALQ-USP).1gilio@usp.br

Submetido em: 15-2-2019

Aceito em:14-8-2020 